\title{
An unusually fast developing giant saphenous vein graft aneurysm
}

\author{
Mutlu Güngör, MD, ${ }^{\mathrm{a}}$ Uğur Küçük, MD, ${ }^{\mathrm{b}}$ Hilal Olgun Küçük, MD, ${ }^{\mathrm{c}}$ and Can Özer, $\mathrm{MD}^{\mathrm{a}}$
}

\begin{abstract}
A 68-year-old man with a history of hypertension and hypercholesterolemia was seen with non-ST-segment elevation myocardial infarction. He had undergone coronary artery bypass grafting in 1996.

Coronary angiography was performed, revealing a giant aneurysm of saphenous vein graft (SVG) to the proximal descending artery (Figure 1,A). Because of its large size, contrast was observed only over the outer border.
\end{abstract}

From the Department of Cardiology, ${ }^{\text {a }}$ Bayındır Ankara Sogutozu Hospital, Ankara, Turkey; Department of Cardiology, ${ }^{\mathrm{b}}$ Van Army District Hospital, Van, Turkey; and Department of Cardiology, ${ }^{\mathrm{c}}$ Van Education and Research Hospital, Van, Turkey. Disclosures: Authors have nothing to disclose with regard to commercial support.

Received for publication Feb 24, 2013; accepted for publication March 4, 2013; available ahead of print April 1, 2013.

Address for reprints: Hilal Olgun Küçük, MD, Van Education and Research Hospital, Van 65000, Turkey (E-mail: olgun.hilal@gmail.com)

J Thorac Cardiovasc Surg 2013;146:1292 $0022-5223 / \$ 36.00$

Copyright $(\underset{2}{ } 2013$ by The American Association for Thoracic Surgery http://dx.doi.org/10.1016/j.jtcvs.2013.03.005
Left ventriculography further delineated the size, borders, and connections of the aneurysm (Figure 1,B). Chest computed tomography with contrast injection demonstrated an $89 \times 118-\mathrm{mm}$ aneurysm within the body of the SVG (Figure 2, $A$ and $B$ ). Interestingly, the same graft was only ectatic on coronary angiography performed a year ago. (Figure 1,C). This giant SVG aneurysm had developed in less than a year. Surgery was offered, but the patient refused intervention and was managed conservatively.

True SVG aneurysm is the result of chronic vascular degeneration due to atherosclerosis. Mild aneurysmal dilation can be found in up to $14 \%$ of all SVGs, but large true aneurysms are rare, with an overall incidence of less than $1 \%{ }^{1}$

\section{Reference}

1. Khalpey Z, Bedzra E, Stella MH, Myers PO. Giant vein graft pseudoaneurysm with pulmonary hemorrhage. J Thorac Cardiovasc Surg. 2012;144:e14-6.

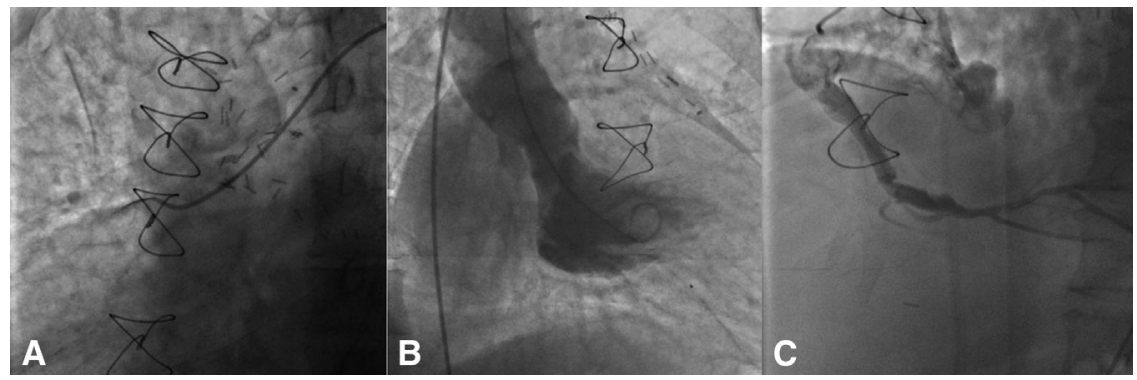

FIGURE 1. A, Coronary angiography revealing giant aneurysm of saphenous vein graft (SVG) to the proximal descending artery. B, Left ventriculography delineating the size, borders, and connections of the aneurysm. C, Ectatic SVG to the proximal descending artery on coronary angiographic imaging performed 1 year ago.
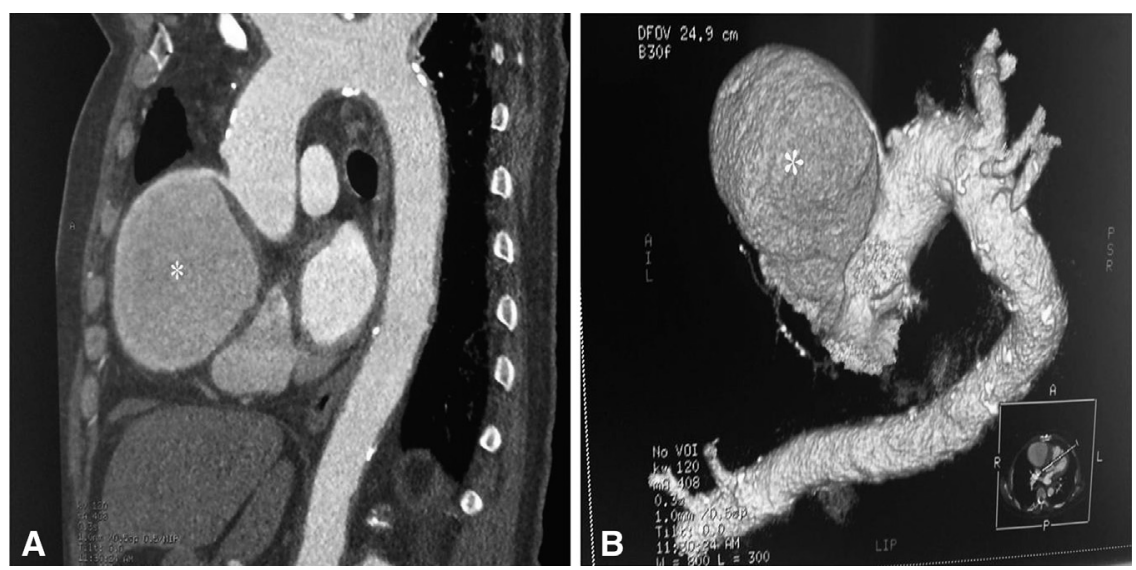

FIGURE 2. A, Contrast-injected coronary computed tomographic images revealing a saphenous vein graft (SVG) aneurysm. B, Reconstructed coronary computed tomographic images of a giant SVG aneurysm. 